\title{
ПРИМЕНЕНИЕ ГЛУБОКИХ ЭВТЕКТИЧЕСКИХ \\ РАСТВОРИТЕЛЕЙ ДЛЯ ЭКСТРАКЦИИ ФЕНОЛЬНЫХ КИСЛОТ ИЗ ЛЕКАРСТВЕННОГО РАСТИТЕЛЬНОГО СЫРЬЯ
}

\author{
О.К. Павельева, М.А. Джавахян \\ Экспериментально-технологический отдел, \\ «Всероссийский институт лекарственных и ароматических растений» (ФГБНУ ВИЛАР), \\ Россия, 117216, Москва, ул. Грина, 7.
}

DOI: 10.19163/MedChemRussia2021-2021-400

E-mail: olesenkamatveeva@yandex.ru

В качестве растворителей при экстракции из растительного сырья традиционно используются спирты, эфиры, кислоты и пр. Применение этих растворителей осложнено необходимостью многоступенчатой утилизации, удаления остатка растворителя из готового продукта и их токсичностью [1].

В настоящее время актуальным является поиск новых экстрагентов, отвечающих принципам «зеленой химии», таким как использование возобновляемых растительных ресурсов и альтернативных растворителей. Глубокие эвтектические растворители (deep eutectic solvents, DES) представляют интерес для современной фармацевтической технологии в качестве альтернативны традиционным органическим экстрагентам. Перспективы их использования обусловлены низкой токсичностью, биоразлагаемостью, возможностью селективного извлечения конкретного вещества и возобновления экстрагента. Процесс экстракции глубокими эвтектическими растворителями основан на замещении молекул растворителя извлекаемыми биологически активными веществами с разрывом существующих водородных связей и образованием новых [2]. При этом на процесс экстракции влияют несколько факторов: сродство между DES и целевыми соединениями, содержание воды, мольное соотношение между исходными молекулами DES, соотношение жидкость / твердое вещество между DES и образцом, а также условия и метод экстракции.

В ходе нашей работы был создан метод ультразвуковой экстракции розмариновой кислоты из змееголовника молдавского. Различные эвтектические растворители показали себя как эффективные экстрагенты для розмариновой кислоты в сравнении с традиционными растворителями.

\section{Литература}

[1] F. Chemat, M.A. Vian, and G. Cravotto, International Journal of Molecular Sciences. 2012.13 (7), p. 8615-27.

[2] E.L. Smith, A.P. Abbott, and K.S. Ryder, Chemical Reviews. 2014.114 (21), p. 11060-11082. 